\title{
In Memoriam Prof. Dr. Severin Daum
}

Prof. Dr. Severin Daum erlag am 11. Januar 2005 im 82. Lebensjahr einer längeren und mit großer Geduld ertragenen Krankheit. Mit ihm verliert nicht nur die deutsche Pneumologie einen frühen Vertreter des Gebiets Kardiorespiration.

Aufgewachsen in der Nähe von Prag, wo sein Vater Präsident des dortigen Patentamtes war, spiegelt der Lebensweg von Daum die Wirren des vorigen Jahrhunderts wider. Nach dem Abitur 1942 war ihm der Weg zum Studium versperrt, da die deutschen Machthaber des „Protektorats“ im Kampf gegen die tschechische Intelligenz alle Hochschulen geschlossen hatten. So begann er das Studium in Jena, musste aber nach drei Semestern ab 1943 für den Lebensunterhalt als Laborant in einem Krankenhaus in Prag arbeiten. Nach dem Ende des Zweiten Weltkriegs begann er 1946 in Prag ein zweites Mal das Studium der Medizin. Nachdem aber 1948 die kommunistische Partei an die Regierung kam, war Daum wegen seiner Religiosität und seiner kritischen Einstellung zum System als Student unerwünscht. Ihm blieb nur übrig, erneut als Laborant zu arbeiten. Erst mit dem Tode Stalins 1953 war ihm die Fortsetzung des Studiums mit Abschluss und Promotion 1956 möglich. Bereits in dieser Zeit wirkte er an der Einrichtung der ersten extrakorporalen Dialyse in seinem Heimatland, der fünften in Europa überhaupt, mit. 1957 wechselte er, von Prof. Dr. F. Herles berufen, in die Kardiologie und beteiligte sich am Aufbau eines Herzkathetermessplatzes in der II. Med. Klinik der Karls-Universität. Reisen ins Ausland blieben ihm aber ebenso verwehrt wie eine Habilitation. Durch die widrigen politischen Umstände gezwungen musste Daum 1962 die Klinik wieder verlassen, kam aber im Institut für Experimentelle Therapie in Prag unter, wo er zum zweiten Mal einen Herzkathetermessplatz einrichten konnte. Hier beschäftigte er sich auch intensiv mit der Bestimmung der Diffusionskapazität der Lunge für Kohlenmonoxid. Am Ende des „Prager Frühlings“ (21. August 1968) konnte Daum mit viel Glück aus der ČSSR ausreisen und

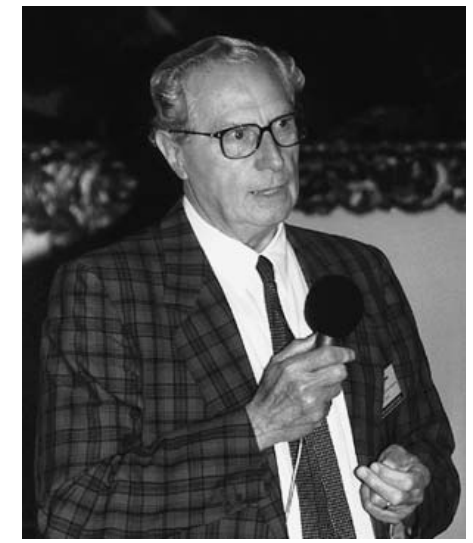

Prof. Dr. med. Severin Daum

kam in die Abteilung von Prof. Dr. H. Herzog am Kantonsspital in Basel, wo er eine Oberarztstelle innehatte. Erst Ende 1968 konnte seine Frau, ebenfalls Ärztin, mit damals noch zwei Kindern ihm nachfolgen. In Basel widmete er sich wiederum der Rechtsherzkatheterisation, zunächst mit dem Katheter nach Grandjean, bald danach mit dem nach Swan-Ganz (beschrieben 1967 bzw. 1970 - Ganz war Landsmann von Daum). 1971 wechselte Daum in das Klinikum rechts der Isar der Technischen Universität München, wo er in der kardiologischen Klinik unter Prof. Dr. H. Blömer eine pneumologische Arbeitsgruppe mit großem Lungenfunktionslabor aufbauen konnte. Dort habilitierte er sich 1972, 1978 wurde er zum apl. Professor ernannt. Jetziges Hauptforschungsgebiet war die einseitige Okklusion eines Pulmonalarterienhauptastes zur präoperativen Simulation einer Pneumonektomie mit dem Katheter nach Dotter-Lukas. Daneben bemühte er sich um die Drucksenkung im Lungenkreislauf bei Cor pulmonale mit verschiedenen Medikamenten. 1990 schied Daum altershalber aus der Klinik aus. 
Auch im „Ruhestand“ blieb Daum weiterhin aktiv. Schon unmittelbar nach dem Fall des kommunistischen Systems in seiner Heimat 1989 knüpfte er Kontakt mit der Karls-Universität und vermittelte eine Kooperation zwischen dieser und der LudwigMaximilians-Universität München. Im Rahmen derer hielt er Vorlesungen in Prag und wurde auch Mitglied des dortigen Wissenschaftsrats. Im August 1991 wurde er vom (damals noch tschechoslowakischen) Präsidenten V. Havel selbst zum ordentlichen Professor an der Karls-Universität ernannt. Das Angebot, die Leitung einer medizinischen Klinik zu übernehmen, schlug er jedoch aus.

Daum hatte in seiner Zeit in der ČSSR trotz schwieriger politischer Bedingungen stets versucht, Kontakt mit den Kollegen im Westen zu halten. Da Reisen zu Kongressen westlicher Gesellschaften nicht erlaubt wurden, forcierte er zusammen mit Kollegen aus mehreren Ländern im Osten wie im Westen die Gründung einer europäischen Gesellschaft, nämlich der Societas Europaea Physiologiae Clinicae Respiratoriae (SEPCR), an deren Spitze das kommunistische System nur einen Franzosen (so Prof. Dr. P. Sadoul) akzeptierte (1990 mit der Societas Europaea Pneumologica (SEP) zur European Respiratory Society (ERS) fusioniert). Ebenso war er später im Westen bemüht, mit seinen früheren Kollegen in Osteuropa und hier insbesondere in der damaligen ČSSR Kontakt zu halten. Er verschaffte ihnen Einladungen zu Kongressen im Westen, unerlässlich für eine Reisegenehmigung durch die Behörden, und besorgte ihnen Reisestipendien. So verwundert es nicht, dass er nach dem Ende der kommunistischen Herrschaft in seinem Heimatland und noch in drei anderen ehemaligen Ostblockländern die Ehrenmitgliedschaft in deren pneumologischen Gesellschaften erhielt. Herausragend sind noch jene in der tschechoslowakischen Gesellschaft für Nephrologie (1990) und in der deutschen Gesellschaft für
Pneumologie (1998). Darüber hinaus erhielt er zahlreiche Auszeichnungen im In- und Ausland. Beispielhaft seien genannt die Verleihung der Robert Koch-Medaille 1966, der Purkynje-Medaille 1998 und die Ehrendoktorwürde der Universität Trnava 2000 (40 km nordöstlich von Preßburg, SK), der ältesten Jesuitenuniversität (gegr. 1635) der k. u. k. Monarchie. Zuletzt erhielt er anlässlich des Kongresses der SEP 2003 in Wien deren Chairman Award - erneut für seine Kontaktpflege mit den Kollegen in den Ostländern. Mehrmals reiste Daum zu Gastvorlesungen in Osteuropa und im fernen Osten.

Severin Daum übte seinen Beruf als Arzt am Krankenbett und als Forscher im Labor mit großer Begeisterung aus. Stets war er bemüht, experimentelle Erkenntnisse in die klinische Tätigkeit zu integrieren. Hierbei kam ihm seine vielseitige Ausbildung sehr zugute. Vielen Kollegen voraus erkannte er frühzeitig die Bedrohung durch Legionellenpneumonie und Pneumonien bei AIDS. Sein größter Einsatz galt aber immer dem Gebiet der Kardiorespiration. Mit den Kongressen „Cor pulmonale“ 1976 und „Interactions between Heart and Lung“ 1987, beide in München, gelang es ihm in einmaliger Weise, Kardiologen und Pneumologen auf europäischer Ebene zusammenzubringen. Neben der klinischen Tätigkeit widmete sich Daum intensiv dem Studentenunterricht. Regelmäßig besuchte er nationale und internationale Kongresse. Alle, die ihn von dorther kennen, werden seine Diskussionsbeiträge, oft verbunden mit dem Hinweis auf schon früher erhobene Befunde, und seine markante Ausdrucksweise in Erinnerung haben. Alle seine Schüler in München und in Prag haben ihm viel zu danken. Die deutsche Pneumologie verliert mit Severin Daum eine herausragende Persönlichkeit und einen jener Vertreter des Gebiets, welche in ihrer aktiven Zeit noch über ein das ganze Fach umfassendes Wissen verfügten. 